\title{
Proceeding
}

Supplementary Issue: Winter Conferences of Sports Science. Costa Blanca Sports Science Events, 22-23 March 2021. Alicante, Spain.

\section{Basic gymnastics program to support the improvement of body stability in adolescents}

\author{
JOSÉ LUIS JAIME-GIL ${ }^{1}$, MAURO CALLEJAS-CUERVO² 4 , LUIS ARTURO MONROY-GUERRERO ${ }^{2}$ \\ ${ }^{1}$ Santander Technology Units, Colombia \\ ${ }^{2}$ Pedagogical and Technological University of Colombia, Colombia
}

\begin{abstract}
Context: The objective of this research was the creation and implementation of a gymnastic program to improve the level of balance in high school students. Method: A diagnosis was made using the direct observation technique and a pre-test by implementing a motion capture platform for the analysis of balance in order to obtain a quantitative and qualitative assessment of the study group. Subsequently, a basic gymnastics program was formed and implemented for a period of 12 weeks. Finally, the impact of the program was evaluated by means of a post-test using the motion capture platform that allowed obtaining a quantitative data and it was contrasted with the field diary by triangulation technique to verify the progress in the level of balance in the students. Results: The quantitative analysis showed improvement in balance on the three-body axes with an average of $+/-5.23^{\circ}$. Furthermore, according to the observations made in the field diaries for each session, they showed that the basic exercises of educational gymnastics, as they were practiced, improved body control. Conclusion: The gymnastic movements practiced within the proposed program caused constant imbalance responses, which originated a positive stimulation in the systems involved in stability improving kinaesthetic awareness, spatial coordination, and postural tonicity in the research group.
\end{abstract}

Keywords: Basic gymnastics; Balance; Pedagogical competences; Biomechanics; Movement sensors.

Cite this article as:

Jaime-Gil, J.L., Callejas-Cuervo, M., \& Monroy-Guerrero, L.A. (2021). Basic gymnastics program to support the improvement of body stability in adolescents. Journal of Human Sport and Exercise, 16(3proc), S1063-S1074. https://doi.org/10.14198/jhse.2021.16.Proc3.24

Corresponding author. Pedagogical and Technological University of Colombia, Colombia. https://orcid.org/0000-0001-98948737

E-mail: mauro.callejas@uptc.edu.co

Abstract submitted to: Winter Conferences of Sports Science. Costa Blanca Sports Science Events, 22-23 March 2021. Alicante, Spain.

JOURNAL OF HUMAN SPORT \& EXERCISE ISSN 1988-5202.

(c) Faculty of Education. University of Alicante.

doi:10.14198/jhse.2021.16.Proc3.24 


\section{INTRODUCTION}

This study arises from research based on emerging teaching methodologies implemented in Physical Education sessions (Trujillo, 2009). It was applied during the development of the gymnastics program, without leaving aside the existing works that suggest the advantages brought by this sport in static and dynamic balance. Conde Ocaña (2014, p. 77) states that this activity "enhances the development of basic skills and abilities of the individual as well as self-confidence, and it brings benefits on body posture, development of the sense of rhythm, emotional stability and security".

It has been demonstrated that "the perceptual-motor stimulus and the basic skills and abilities that are performed in Gymnastics influence the acquisition of a correct posture, which is developed through specific work on the body scheme, through the perception of the body itself (tonicity and posture), and the perception of the environment (spatio-temporal structure, laterality and rhythm) in addition to coordination in basic motor patterns (displacements, jumps, turns, balances), highlighting flexibility and muscle strength as an important factor in maintaining a correct posture" (Conesa Ros \& Martínez Gallego, 2017, p. 38).

There is certainly evidence of a positive effect gymnastics has on postural control. "Artistic gymnastics training positively favours body harmony skills, which enables gymnasts to perfectly preserve their balance, even in difficult circumstances, both in competition and in different conditions" (Ayşe Oya, Manolya, Ufuk, \& Salih, 2012, p. 1261). "In gymnasts there is evidence supporting that systematic practice and repetition in specific gymnastics tasks involving balance, in the different phases of a subject's sporting life (learning, training or competition), leads to an improvement in postural skills that are associated with an improvement in the sensitivity of sensory receptors or better integration of information by the structures responsible for regulating postural control" (Guimaraes Ribeiro, Hernández Suárez, Rodríguez Ruiz, \& García Manso, 2015, p. 55-56).

It is known that practicing some sport improves conditional and coordinative physical abilities depending on the stages of development of the subject; in this sense, basic gymnastics is a discipline that has greater advantage over others, for its characteristics and movements easily practiced in reduced spaces, leaving a high impact on physical development; so it is, that it was demonstrated in athletes practicing sports such as soccer and basketball versus gymnasts, variations in balance performance, whose "results in scores of errors in balance for the gymnastics group were 55\% lower than those of the basketball group, while in the soccer group scores were 7\% higher, than in the latter group" (Eadric , Joshua , John , \& Edward , 2007, P. 42).

It should be noted that age plays a fundamental role in the development of stability and the stimulus to be applied in the appropriate period, these may have greater effect in more sensitive stages, evidenced in gymnasts from 4 to 8 years old, which improved significantly, not only in static bipedal-standing position, but also in unipedal positions. (Tanasă, Dumitru, \& Budacă, 2020).

It is easy to refer to gymnastics as a behaviourist activity, rigid in its methodology and with a strong character, a position that is trying to be change by implementing educational activities such as the dimensions, "Know, Know-how, and Know-how-to-be" (Romero Cereso, 2009).

Currently, the modification of syllabus has affected the practice of various sports and recreational activities. According to Soler Pérez (2008), "the increase in technology and its bad use by schoolchildren tends to encourage a sedentary lifestyle". The natural environment in which human beings are surrounded brings that they end up accommodating themselves to the demands of the environment. This vision is shared by authors 
such as Fernandez (1941, p.22) who affirms that "accommodation does not imply perfection or improvement, since there are conditions of the environment that are notably harmful and that force the organism to a series of fatal compensations for its physiology, thus explaining the fact that there are races that we could call regressive, that means biological decline or degeneration". This degeneration or decline would begin at school age, based on the above mentioned.

As it is mentioned by Aguilar González (2012, p. 6), "the three main activities of private school children are: watching television, going out, and surfing the Internet". From the point of view in the physical condition, it causes several consequences, allowing an accommodation of the body causing it not to experience the different external forces that interact in a standing position, causing a decompensation in the domain of the body; a problem that increases over the school age. "The student tends to give up much of the time that he used to dedicate to play, to stay at the school desk" (Fernandez Martinez, 1945, p. 22). This causes consequences not only in stability, but also in "corrupt postures and unadopted movements that generate shortening of the posterior muscles, which implies a decrease in strength" (Frères \& Mairlot, 2000, p.45); causing body loads not to be properly distributed, generating physical imbalances evident in this population during the movements performed and the inability to react adequately to the loss of body control.

This research proposes a basic gymnastics program to support the improvement of body stability in adolescents. The article is structured in the following subsections: First, the materials and the method used for the development of this research are mentioned. Then, the results of the implementation of this program are presented, followed by a discussion of the results obtained. Finally, the conclusions are presented.

\section{MATERIALS AND METHODS}

This subsection describes the research approach and design applied, it presents the instruments and materials used for the tests and the implementation of the basic gymnastics program, then it describes the sample and how it was selected, and finally it describes the research procedure applied.

\section{Research approach: Mixed}

"Mixed methods refer to a single study that uses multiple or mixed strategies to answer research questions and/or confirm hypotheses" (Pereira Pérez, 2011, p.17). In this sense, this study used a process that collects quantitative data and qualitative data, analyses and links these characteristics to respond to the problem statement. "It is the complementation of qualitative and quantitative approaches, since quantity and quality are nothing more than complementary aspects of the same fact" (Velásquez Fernández \& Rey Córdova, 2007).

\section{Research design: Explanatory - sequential (QUAN - QUAL)}

This design is of the Quan-Qual type, due to the sequentially in which the data collection instruments are applied; according to Castañer Balcells et al. (2013, p 32), in this type of design the quantitative order data (QUAN) are predominant and the qualitative order data (QUAL) are complementary in the analysis of the information.

\section{Instruments and techniques for data collection}

The elements established to collect data in this research corresponds to the proposed approach under two perspectives, quantitative and qualitative, these allow the collection of relevant data on variables, events, contexts, objects involved in the research. Specifically, two types of instruments were applied: 
- Quantitative: Capture and analysis of movement.

IMOCAP inertial and magnetic motion capture platform, which is described in more detail in Callejas Cuervo et al. (2017).

- Qualitative: Participant observation.

"Field diaries": This qualitative research technique allows identifying aspects such as verbal, didactic and mathematical language (Medina Rivilla, De La Herrán Cascón, \& Domínguez Garrido, 2014). The diary format was devised from the needs of the research based on the proposal of Villegas Ramos (2004, p.85). It is established by means of comparative tables which contain: The observed experiences, Reflections of the experiences and Study categories: CAT 1 Basic Gymnastics Pedagogical Program, CAT 2 Static balance. This, in order to generate a qualitative analysis in each session.

\section{Materials used in the study}

The following were the tools and instruments used for the development of the research: IMOCAP platform; Kalley K-BD f50 digital scale, field diaries, balance beam, teaching aids: palm and sole guide silhouettes; 1.5 $\mathrm{kg}$ load cushion; $2.5 \mathrm{~kg}$ medicine ball, Pilates ball, trampoline, ropes, hurdles, hoops.

\section{Participants}

The sample corresponds to tenth grade students from a public school in the city of Tunja, Boyacá, Colombia. The age range is between 14 and 18 years old. According to the inclusion criteria, participation was limited to seven students. The reduced work unit makes it a characteristic of a mixed method, according to Castañer Balcells et al. (2013), "this perspective requires delimiting the object of study with greater amplitude to cover all its complexity". This is due to the fact that the research is not only limited to the collection of data of different nature, but also implies combining inductive and deductive logic.

Criteria for inclusion in the work unit

1. Ability to walk independently. That is, should not use external orthopaedic elements, to maintain static bipodal balance with eyes open.

2. Not having any contraindication or disease that prevents them from undergoing any of the assessment tests.

3. To have previously filled out the informed consent form.

The criteria determined is based on certain pre-established features in clinical practice for the assessment of static and dynamic equilibrium in healthy subjects, and the last criterion respects the ethical norm based on the autonomy of the person, who has the right to decide whether or not to participate in this research.

\section{Anthropometric measurements of the intervened population}

Anthropometric measurements were taken in order to determine the greatest possible homogeneity, which is necessary in these studies, as a way of controlling possible extraneous variables or "factors affecting balance" (Contreras Rodríguez, 2011). Age: Mean 15 years, standard deviation 1.11. Height: Mean $1.62 \mathrm{~cm}$, standard deviation 0.059. Mass: Mean $54.1 \mathrm{~kg}$, standard deviation 6.89. BMl: Mean 20.55, standard deviation 2.03 .

\section{Research procedure}

Several stages were established, which were fundamental to identify, plan, develop and evaluate the basic gymnastics training program and determine the impact it has on the level of balance, these were: 


\section{- Diagnosis}

The diagnosis was carried out through direct observation inside the classroom "gymnastics room" in the development of a regular class, this in order to identify aspects in which there is some difficulty or abnormality. During the observations, an incorrect execution of gymnastic movements was found, attributed to a pedagogical vacuum in teaching, the loss of balance was identified with ease, and body insecurity, something unfortunate at this stage of motor development (Martin, Nicolaus, Ostrowski, \& Rost, 2004). Once the observation was done, a "pre-test" of Balance "TEEC" was applied, which is described in detail in (CallejasCuervo, Jaime Gil, \& Monroy Guerrero, 2020).

\section{- Elaboration of the pedagogical program}

It is constituted by three dimensions of knowledge "theoretical knowledge of an academic area of the professional field "know", "know-how" which refers to applying knowledge to concrete situations, and "knowhow-to-be" which refers to personal characteristics and attitudes towards oneself, towards others and towards what one does" (Romero Cereso, 2009). The format of the physical education class program was taken from the proposal (Jaimes, Monroy Guerrero, \& Alvarez Mora, 2012). The pedagogical strategies used in the sessions correspond to traditional styles, individualizing styles, creative style, participatory styles and cognitive styles (Delgado Noguera, 2015). A more detailed description of the construction of the pedagogical program is evidenced in (Callejas-Cuervo, Jaime-Gil, \& Monroy-Guerrero, 2018).

- Structure of the gymnastics session

Initial: joint mobility is performed to subsequently perform muscle exercises predominantly isometric contractions focused on the "core". Abdominal, lumbar, pelvic, gluteal and deep spine muscles with "long" contractions (10 or more seconds) with fewer repetitions, "precise stimulus to increase static strength and joint stability" (Schott, McCully, \& Rutherford, 1995) using submaximal loads such as own body weight.

Central: Teaching and practice of gymnastic movements such as coordinated multidirectional displacements on the floor, rolls in directions to the anteroposterior axis, alternating monopodial jumps, jumps with turns on the craniocaudal axis in both directions, trampoline jumps on the anteroposterior axis, inverted jumps with palmar and craniopalmar supports, displacements on the balance beam, multidirectional lateral wheels, and gymnastic schemes involving three of the above mentioned movements depending on the week of intervention.

Final: In this section static stretches were executed, both active and passive. With a ratio of $1 / 1$ in execution time and rest, 10 seconds of execution, 10 seconds of rest. The stretching focused on flexion and hyperextension of the trunk or "core" stretching to the quadriceps muscle group, gluteus, iliotibial band, gastrocnemius and tibial muscles, with involvement in the development of skin awareness, conscious touch, "displacement of the hands on the skin of the joint", experience of conscious transport-reflex: "straightening in the spine", principles of the eutonia method: control positions, Mézières method stretches focusing on the fifth muscular chain, anteroposterior and posteroanterior, proposed by G. Struyf. "performing stimulus such as stretching of the plantar musculature, activation of the quadriceps by working in semi-flexion positions, such as squats at $90^{\circ}$ with opening of the squats, load on the top of the skull, using a bag weighing no more than 500 grams, visualization of the spine by means of a mirror, in the sagittal plane, to consciously stretch, all the posterior muscles of the back" for more information on the methods described, consult in (Frères \& Mairlot, 2000, p. 48). Complementing the work with asanas or yoga positions focused on maintaining balance (Mittra, 2012). 
- Implementation of the basic gymnastics program.

The program consists of twelve class sessions, including the sessions where the pre-test and post-test were conducted. The duration of the gymnastics sessions is pre-established by the educational institution, two hours per week. Particularly this work tries to be compatible with the current lifestyle in these ages and the school environment, and it seeks to foster critical thinking in the subject, increasing the academic load, enhancing "elective" sports. In each intervention session, except the test sessions, is applied a participantobservation, recorded through the field diaries.

\section{RESULTS}

The results are presented from two approaches: In the first one, it is objectively explained the measurements obtained by IMOCAP platform and their respective quantitative analysis, and in the second approach, they are presented in qualitative manner using the field diaries and the triangulation method.

\section{Quantitative approach}

The average movement generated in the pre-test for the three body axes, denoted a value of $10.94^{\circ}$. The data obtained in the post-test show a value of $5.42^{\circ}$ of average movement, indicating $5.53^{\circ}$ of progress. For its part, the Craniocaudal axis recorded average pre-test value of $13.84^{\circ}$, after the intervention program the records denote $6.50^{\circ}$ showing an improvement in the stability of $7.35^{\circ}$, meanwhile the Mediolateral and Anteroposterior axes registered values of $8.47^{\circ}$ and $10.52^{\circ}$ respectively in the pre-test, the value reached in the post-test indicates that Mediolateral axis has an average of $4.77^{\circ}$, with a difference of $3.70^{\circ}$. On the other hand, the Anteroposterior axis obtained an average of $4.98^{\circ}$, with a difference of $5.54^{\circ}$, as can be seen in Figure 1.

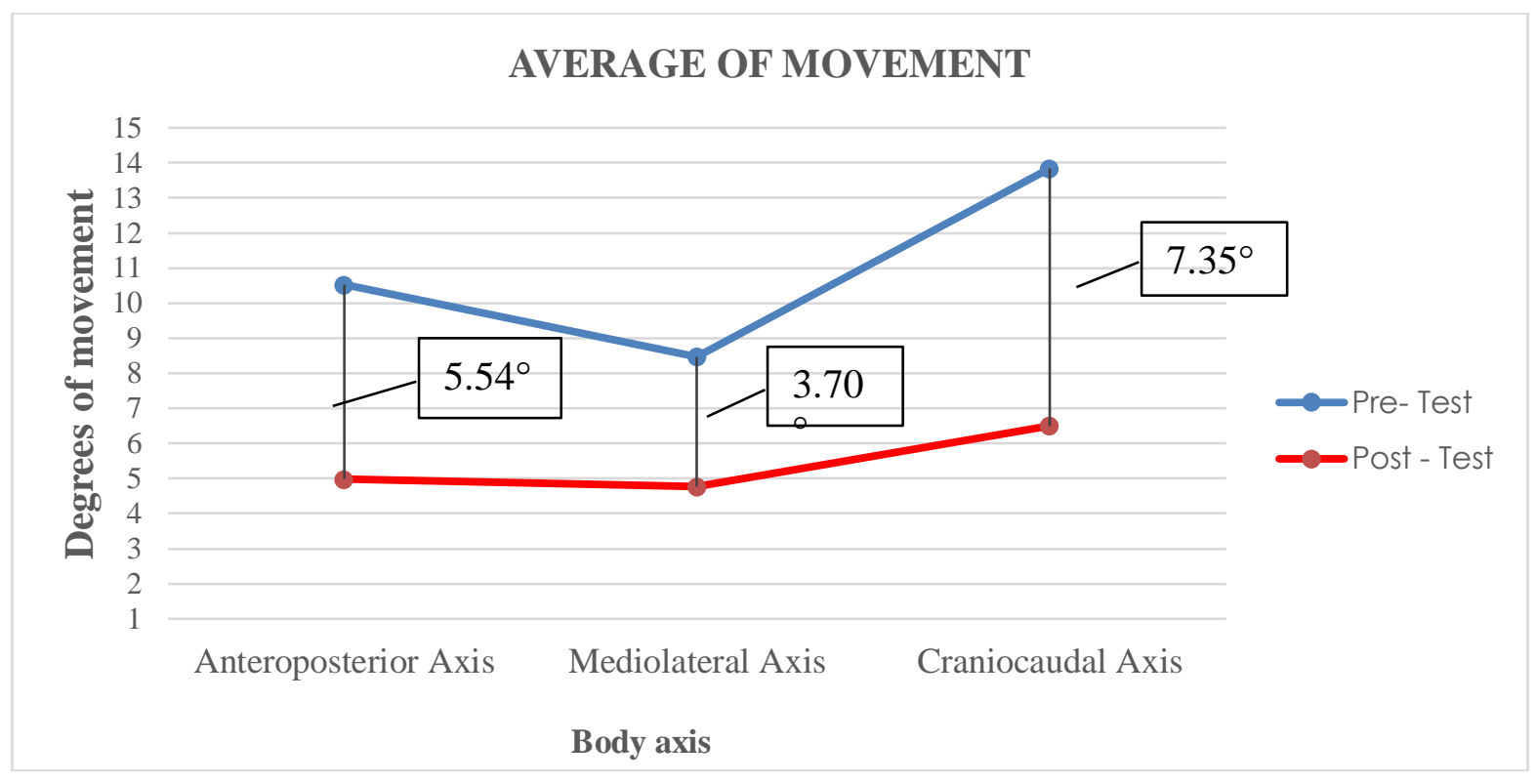

Figure 1. Average movements ranges.

Thus, Figure 2 shows the average percentage of progress in the stability of the group for each body axis.

The configuration of the test scenarios and the complete description of the test results are fully documented in (Callejas-Cuervo, Jaime Gil, \& Monroy Guerrero, 2018). 


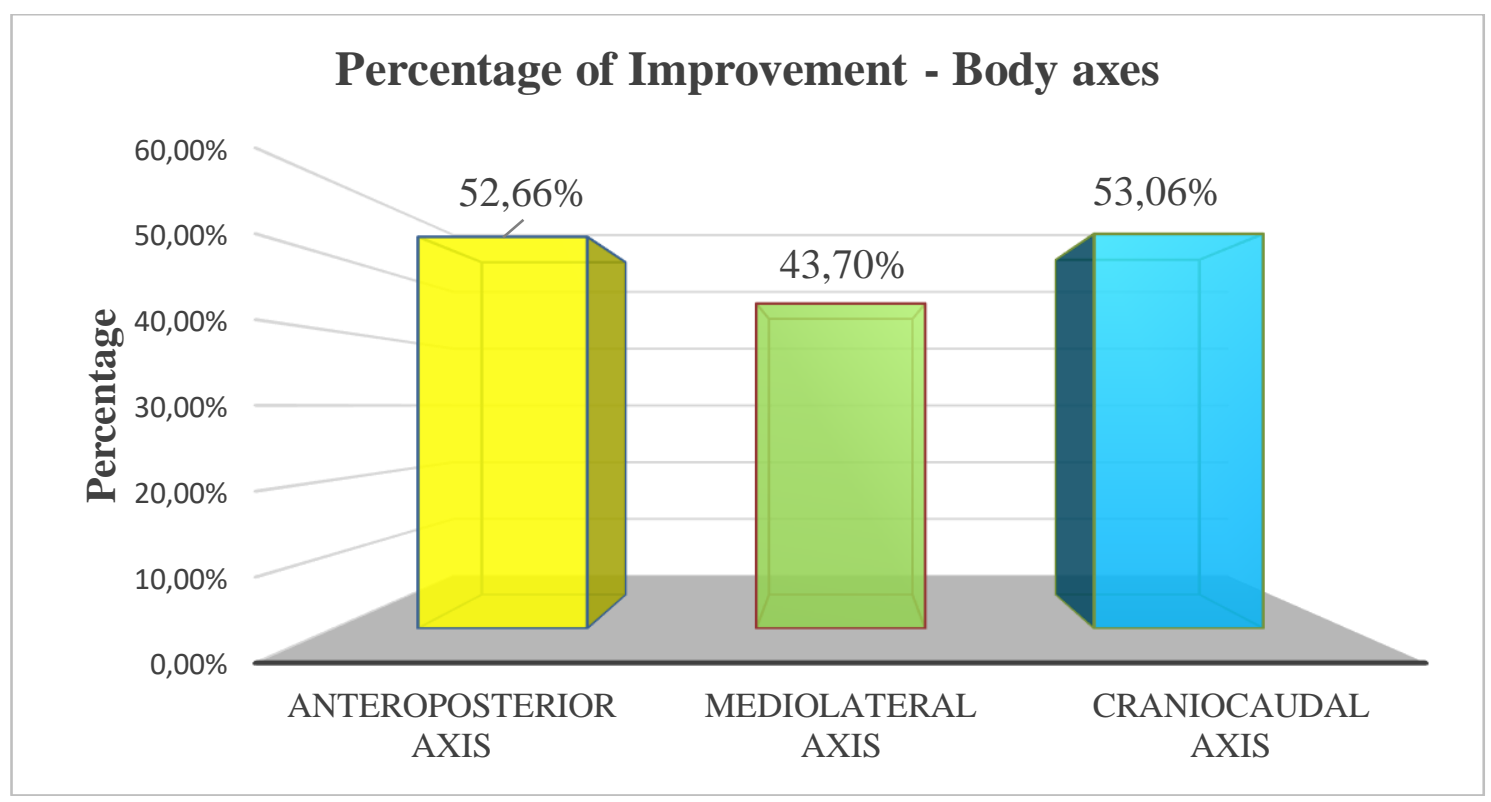

Figure 2. Percentage of improvement in the three body axes.

\section{Qualitative approach}

The pedagogical strategies implemented in the sample group promoted the development of the three competencies. In Know competence, the explanation is done by organizing the group in free formations in circle and semicircle, indicating the importance of methodical steps in the movements. This has a positive effect on the students, because the concept is the pillar for the beginning of knowledge, it makes them create mental constructions or self-projections, by means of which the understanding of the movement is reached. This competence awakens curiosity to know methodical steps of other gymnastic exercises with greater complexity such as "head pine" and "inverted hands", as well as the usefulness and importance of the respective grips to assist the partner with fundaments.

The know-how competence puts into practice the methodological steps, making evident in students a simpler execution of the movements of high complexity, encouraging and motivating a constant repetition of the actions to reach the final movement "perfection of the movement", giving a feeling of fullness. This competence not only motivates practice, but also stimulates the correct execution of the corresponding safety grips for students who cannot yet perform the exercise, making the movements safer, more remarkable, and over time, the technical execution is improved, which stimulates body safety and therefore an execution of the movements without assistance.

In know-how-to-be competence, referred to behaviours, it was evidenced that progressively improved the attitudes of respect and admiration for the more advanced subjects when performing gymnastic movements; this create bonds of friendship and trust in the less advanced students towards them when performing support functions in the execution, while the acts of responsibility and temperament were forged in the students who perform assistance, understanding the degree of responsibility that they have acquired.

The aspect of monopodial static balance, referred to the base of support of the dominant joint, shows a remarkable improvement in stability; the variations of body movement are smaller, through the practice of movements such as lateral wheel and the different displacements in the roll exercises in the anteroposterior axis, ending in monopodial positions. 
In complex exercises such as "the fifth", "Olympic pine", "head 'pine", and "fish jump" and "head jump", executed in gymnastic schemes, the aerial phase stimulates the kinaesthetic system, improving its corporal performance producing more aesthetic and controlled movements.

During the falling phase, due to the different forces exerted on the body, the most efficient and effective stability techniques are forged, such as semi-flexion of the lower joints, tonic contractions of the "core", better support of the soles of the feet, showing the extension of the toes on the ground and less trembling in the ankle joints.

The above mentioned agrees with the results of (Blenkinsop, Matthew, \& Michael, 2017, p. 6 -7) "During standing balance, the most prevalent control strategy employed was the ankle strategy, followed by the hip strategy, and the knee strategy which was the least employed."

On the other hand, yoga asanas, as a final fragment of the session, make breathing more controlled in balanced positions, a positive aspect that reduces feelings of insecurity, and also it develops the concentration of the movements performed during the seconds that the asana lasts. As stated by Espinoza Navarro, et al. (2009, p. 29), "all or most of the remedial programs should, therefore, incorporate according to their possibilities, breathing exercises, coordination, correct posture and relaxation to stimulate balance". The planks or isometric exercises focusing on the muscles of the fifth muscular chain proposed by G. Stuyft, show an outstanding support of the position, increasing muscle tension and contributing to maintain a better posture, this tension favours static balance in bipedal position.

The active stretching with the Mézières method, always keeping a touch with the body extremities, helped to be aware of the volume of the body, allowing to obtain a relaxation in the joints, improving the reactions to the loss of stability.

Table 1. Triangulation of information.

\begin{tabular}{|l|l|}
\hline QUANTITATIVE & QUALITATIVE \\
\hline Process described in the quantitative results section. & Process described in the qualitative results section. \\
\hline General evaluation: \\
According to the data obtained in the "Static Balance Test with a Kinematic Element" and those recorded \\
in the field diaries, it is precise to affirm that during the process of teaching and practice of gymnastic \\
movements through the teaching styles and their strategies, allowed to improve the approach of \\
competencies for life in each of the students, enriching their behaviours, particularly in relation to human \\
ethical values. In addition, these competencies promote the theoretical learning of the movements \\
performed, understanding the methodological steps of each one, which promoted massive practice, and \\
also served as a support for the safety of the beginner student during the execution of a certain movement. \\
Through the practice of gymnastic schemes involving complex exercises, according to the degree of \\
execution, it is possible to precise that body control improved, which is confirmed by the data obtained by \\
the "TEECC" whose analysis in the variations of the movements were lower for the three body axes, as \\
well as the records in the ranges of rotations, inclinations, flexions and dorsolumbar extensions, during the \\
post-test. Finally, it is confirmed that the practice of the physical activities proposed in this study allow \\
improving static balance.
\end{tabular}




\section{Triangulation of information}

As a final part of the process of obtaining results by implementing the triangulation technique, a summary was made with the information recorded in each of the field diaries, analysing the experiences observed in the classroom sessions and why, "reflections" of the phenomena described in them, which refers to the qualitative part.

In the quantitative part, the ranges of movement captured by the "IMOCAP" platform were analysed, data obtained in degrees of movement for each test, in the three body axes of each participant, performing a descriptive statistical analysis.

Table 1 shows the final result of the information triangulation process, in which the quantitative analysis is complemented by the qualitative analysis.

\section{DISCUSSION}

It was evident the limited intervention time of the program, which possibly could have obtained a better result. In fact, most training plans that are structured to perform an intervention, implement three or more hours per week, depending on the physical capacity to be stimulated, although there is evidence that, in "systematic and permanent exercise programs for six weeks three times per week, achieve a significant increase in muscle strength, improving scapular stability and a more upright posture" (Espinoza Navarro, et al., 2009, p.29). It is difficult to question that the two-hour weekly interventions to improve a coordination capacity are effective, because there are very few studies developed to provide academic support and generate a concrete affirmation, this is one the reason for this research.

Despite the above mentioned, to achieve a transformation of the physical and psychic functional systems that occur under the effect of external loads on the individual and lead him towards a higher level of performance in the coordinative physical abilities, there are few studies found that have been developed in a natural environment such as Physical Education classes practicing basic gymnastics movements, with so little time for work. Despite of it, there is a high concordance of the results obtained in this research with the results recorded in the study of Jaroslav et al. (2018, P.25), which showed that balance training with a frequency of 30 minutes per week during 14 weeks can be a valuable complement to the usual training of elite gymnastics athletes and improves the postural stability of the body.

This allows to say that the intervention time implemented in this research may be the minimum adequate to improve coordination capacity such as static balance. For Subirats Bayego et al. (2012), dedicating 2 sessions of 10 minutes per week performing 8 to 10 exercises for a coordination capacity, such as flexibility of most muscle and tendon groups, are maintained. In addition, it could be possible to say that coordinative capacities in general could improve to an acceptable level with little work time, but with an excellent quality of exercises planned in the programs applied.

The aforementioned allows to deduce that, despite the few hours of intervention, there are positive stimulus. Authors such as Espinoza Navarro et al. (2009, p. 26) argue that, "the implemented methodological strategy of 2 classes per week, with a duration of 30-45 minutes approximately, significantly corrects posture". On the other hand, Frères \& Mairlot (2000), in their book Keys and Masters of Posture, a bad posture can affect the balance of the human being. In this sense, it cannot be affirmed that the program, not only allowed to decrease the ranges of movement but also the students were able to improve the postural adjustment with the exercises of re-education and awareness of their own body. 
After the interventions focused on performing movements common in basic gymnastics, it can be affirmed that this discipline contributed to improve stability, which is evidenced in the results obtained in the post-test. Ahomen (2001, p. 233), explains that "in specific disciplines such as figure skating and gymnastics, muscular balance is shown in the movements performed in the correct postures, this performance produces an optical impression". The constant imbalances in the practice and repetition of the basic movements implemented, produce positive responses on body control.

Referencing the above stated, Guimaraes Ribeiro et al (2015, p.55-56), indicate that "there is evidence to support the hypothesis that practice and systematic repetition in specific balance tasks, in the different phases of the sporting life of a subject, lead to obtain a sensitivity of sensory receptors or better integration of information by the structures responsible for regulating postural control". This may explain the decrease in movement recorded in the group analysed, specifically in third test, monopodial balance with eyes open, where ranges of lower amplitude or oscillations in the different body axes are obtained during the post-test.

In contrast to the mentioned above, the ranges of movement obtained in the Mediolateral axis were lower than the movement of the Anteroposterior and Craniocaudal axis. These results are interesting because they do not agree with the study of Leirós Rodríguez et al. (2015), where higher kinematic values were obtained unlike the other two axes. Although this result is similar with the study of Andrzej et al. (2015, p 120), who argued that, in the variations of movement, "it should be highlighted the fact that the fluctuations in the transverse axis were clearly larger than in the sagittal both among younger gymnast athletes and among older ones", clarifying that this result is compared in inverted hands position. Nevertheless, the result of this research allows us to glimpse that as the years go by, the mediolateral axis may be more susceptible to imbalances; this mean that, stability is more easily lost.

Finally, in the observation record that was made during the teaching and practice process, it was evidenced that the movements of greater difficulty, sustained and momentary inverted such as "pine head", "lateral wheel", and "handstand, stimulate body stability involving the muscle chains that participate in the support of the standing posture, finding a strong relationship with the arguments of Jarosław et al. (2018, p. 139), which argue that statistically significant correlations were found between the variables obtained in standing position and handstand of a body".

\section{CONCLUSIONS}

The repeated practice of basic gymnastic movements such as Rolls and the different displacements in the anteroposterior axis, inverted supports, planks, turns, jumps and multidirectional displacements, with low loads "work - rest ratio 1/1", stimulate stability. These movements make up the gymnastic schemes making the body experience different sensations of imbalances generated at the end of the executions, in a way that, as time goes by, responds better to instability situations. These gymnastic activities allow the development of kinaesthetic awareness and spatial orientation, as it is evidenced in the results of this research.

The pedagogical strategies implemented during the program intervention allowed most of the group to improve their understanding of the topics of the proposed movements. It was also evident that, styles such as the traditional and small groups, allow a better organization of the intervention sessions in such a way that the learning rate of each member does not go unnoticed, and the shortcomings during the execution of the gymnastic movements are taken into account, allowing the teacher to intervene opportunely to explain the frequent errors observed. 
Finally, it can be affirmed that the traditional, individualized, creative, participative and cognitive styles encourage the development of the three knowledge competencies, because the students understand the purpose of the methodological steps, as well as the respective grips; this helps in the sessions to carry out a continuous execution of the planned movements. In this way, practice is encouraged, and it can be precisely affirmed that they promote more interaction between the teacher and the students; this interaction leads to changing the way they relate to each other, measuring the actions, thoughts and acts.

\section{REFERENCES}

Aguilar González., L. E. (2012). Los escolares como consumidores y usuarios de medios y tecnologías. Diálogos sobre educación., 1-20.

Ahomen, J. (2001). Kinesiología y Anatomía Aplicada a la Actividad física. España: Paidotribo.

Ayşe Oya , E., Manolya , A., Ufuk , A., \& Salih , P. (2012). Investigating of relationship between balance parameters and balance lost of elite gymnastics on balance beam. Journal of Human Sciences, 1261-1270.

Blenkinsop, G. M., Matthew, T. P., \& Michael, J. H. (2017). Balance control strategies during perturbed and unperturbed balance in standing and handstand. Royal Society Open Science, 1-12. https://doi.org/10.1098/rsos.161018

Callejas-Cuervo, M., Jaime Gil, J. L., \& Monroy Guerrero, L. A. (2020). Balance analysis in adolescents based on a motion capture platform. Journal of Human Sport and Exercise., 504-515. https://doi.org/10.14198/ihse.2020.15.Proc3.23

Callejas-Cuervo, M., M. Gutierrez, R., \& I. Hernandez, A. (2017). Joint amplitude MEMS based measurement platform for low cost and high accessibility telerehabilitation: Elbow case study. Journal of Bodywork \& Movement Therapies, 574-581. https://doi.org/10.1016/j.jbmt.2016.08.016

Callejas-Cuervo, M., Monroy Guerrero, L., \& Jaime Gil, J. L. (2018). Tecnologías de captura de movimiento Propuesta de un método para la valoración del Equilibrio en un programa Pedagógico de Gimnasia Básica. Tunja: UPTC.

Castañer Balcells, M., Camerino foguet, O., \& Anguera Argilaga, T. (2013). Métodos mixtos en la investigación de las ciencias de la actividad física y el deporte. Apunts. Educación Física y Deportes, 31-36. https://doi.org/10.5672/apunts.2014-0983.es.(2013/2).112.01

Conde Ocaña, H. L. (Sep de 2014). La gimnasia artística y su incidencia en la preparación física de los estudiantes de décimo año de educación general básica, paralelos A y B del Colegio Técnico Baeza del cantón Baeza. Provincia Del Napo, Ecuador: Univercidad Tecnica de Ambato.

Conesa Ros, E., \& Martínez Gallego, F. (2017). Una modalidad saludable de gimnasia en edad escolar: La gimnasia estética de grupo. E-balonmano.com: Revista de Ciencias del Deporte., 37-52.

Contreras Rodríguez, C. (2011). La coordinación y el equilibrio dentro de la Educación Física actual. Efdeportes, $1 / 1$.

Delgado Noguera, M. Á. (2015). Los estilos de enseñanza de la Educación Física y el Deporte a través de 40 años de vida profesional. Retos. https://doi.org/10.47197/retos.v0i28.35532

Eadric , B., Joshua , C., John , K., \& Edward , M. (2007). Comparison of Static and Dynamic Balance in Female Collegiate Soccer, Basketball, and Gymnastics Athletes. JAT Journal Of Athletic Training, $42-46$.

Espinoza-Navarro, O., Valle, S., Berrios, G., Horta, J., Rodríguez, H., \& Rodríguez, M. (2009). Prevalence of postural alterations and effects of a program to improve the posture in children from Arica-Chile. International Journal of Morphology, 25-30.

Fernández, F. (1941). Tecnica de la gimnasia educativa. Toledo: Catolica Toledana.

Frères, M., \& Mairlot, M. B. (2000). Maestros y claves de la postura. Barcelona.: Paidotribo. 
Guimaraes Ribeiro, D., Hernández Suárez, M., Rodríguez Ruiz, D., \& García Manso, J. M. (2015). Efecto del entrenamiento sistemático de gimnasia rítmica sobre el control postural de niñas adolescentes. Revista Anda luza de Medicina del Deporte, 54-60. https://doi.org/10.1016/i.ramd.2014.11.001

Jaimes Jaimes, G., Monroy Guerrero, L. A., \& Alvarez Mora, A. A. (2012). Las competencias cognitivas y emocionales desde la educacion fisica. Armenia, Colombia: Kinesis.

Jaroslav , K., Tomáš, M., \& František, Z. (2018). The effect of intervention balance program on postural stability. Science of Gymnastics Journal, 17-28.

Jarosław , O., Przemysław , B., Ewa Puszczałowska, L., \& Leon , B. (2018). Balance in handstand and postural stability in standing position in athletes practicing gymnastics. Acta of Bioengineering and biomechanicS, 139-147.

Leirós Rodríguez, R., Arce Fariña, E., \& García Soidán, J. L. (2015). Estudio piloto para la valoración del equilibrio en mujeres adultas con un elemento cinemático. Retos, 90-93. https://doi.org/10.47197/retos.v0i28.34899

Martin, D., Nicolaus, J., Ostrowski, C., \& Rost, K. (2004). Metodología general del entrenamiento infantil y juvenil. Barcelona: Paidotribo.

Medina Rivilla, A., De La Herrán Cascón, A., \& Domínguez Garrido, M. (2014). Fronteras en la investigación de la didáctica. Madrid: UNED.

Mittra, D. (2012). ASANAS 608 Yoga Postures. California: New World Library.

Pereira Pérez, Z. (2011). Los diseños de método mixto en la investigación en educación:. Educare, 1529. https://doi.org/10.15359/ree.15-1.2

Romero Cereso , C. (junio de 2009). Definición de módulos y competencias del maestro con mención en Educación Física. Revista Internacional de Medicina y Ciencias de la Actividad Física y el Deporte., 9(34), 179-200.

Schott, J., McCully, K., \& Rutherford, O. (1995). El papel de los metabolitos en el entrenamiento de fuerza. II. Contracciones isométricas cortas versus largas. Revista Europea de Fisiología Aplicada y Fisiología del Trabajo, 337-341.

Tanasă, R., Dumitru, I., \& Budacă, M. (2020). The effects of gymnastics training on static balance among children aged 4 to 8 . Series IX: Sciences of Human Kinetics, 111-118. https://doi.org/10.31926/but.shk.2020.13.62.1.14

Trujillo, F. (2009). Retrieved from efdeportes web site: http://www.efdeportes.com

Velásquez Fernández, Á. R., \& Rey Córdova, N. G. (2007). Metodología de la Investigación Científica. Lima: San Marcos.

Villegas Ramos, E. L. (2004). Investigación y práctica en la Investigación y práctica en la. Valencia: Nau Llibres. Edicions Culturals Valenciales, S.A.

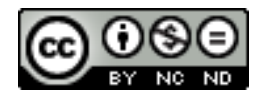

This work is licensed under a Attribution-NonCommercial-NoDerivatives 4.0 International (CC BY-NC-ND 4.0). 